\title{
Fetal Liver
}

National Cancer Institute

\section{Source}

National Cancer Institute. Fetal Liver. NCI Thesaurus. Code C34169.

The development of the liver after the eleventh week of gestation until the time of birth. 